\title{
Diarylfluorene-Based Shape-Persistent Organic Nanomolecular Frameworks via Iterative Friedel-Crafts Protocol toward Multicomponent Organic Semiconductors
}

\author{
Guang-Wei Zhang, ${ }^{1}$ Long Wang, ${ }^{1}$ Ling-Hai Xie, ${ }^{1}$ Xiao-Ya Hou, \\ Zheng-Dong Liu, ${ }^{1}$ and Wei Huang ${ }^{1,2}$ \\ ${ }^{1}$ Center for Molecular Systems and Organic Devices (CMSOD), Key Laboratory for Organic Electronics and Information Displays \\ (KLOEID) and Institute of Advanced Materials (IAM), Nanjing University of Posts and Telecommunications (NUPT), \\ Nanjing 210046, China \\ ${ }^{2}$ Jiangsu-Singapore Joint Research Center for Organic/Bio-Electronics and Information Displays and Institute of Advanced Materials, \\ Nanjing University of Technology, Nanjing 211816, China
}

Correspondence should be addressed to Ling-Hai Xie; iamlhxie@njupt.edu.cn and Wei Huang; iamwhuang@njupt.edu.cn

Received 4 January 2013; Accepted 11 February 2013

Academic Editor: Hongmei Luo

Copyright (C) 2013 Guang-Wei Zhang et al. This is an open access article distributed under the Creative Commons Attribution License, which permits unrestricted use, distribution, and reproduction in any medium, provided the original work is properly cited.

\begin{abstract}
We describe bottom-up fluorenol approach to create soluble covalent organic nanomolecular architectures (ONAs) as potential multicomponent organic semiconductors (MOSs). BPyFBFFA as a typical model of ONAs and MOSs exhibits a persistent chairshaped geometric structure that consists of hole-transporting triphenylamine (TPA), high-efficiency terfluorene, and high-mobility pyrenes. BPyFBFFA was synthesized via the intermediates PyFA and BPyFA with iterative Friedel-Crafts reactions and Suzuki crosscoupling reactions. BPyFBFFA behaves as an efficient blue light-emitter without the low-energy green emission band. Complex diarylfluorenes (CDAFs) are promising candidates for nanoscale covalent organic frameworks and MOSs. Friedel-Crafts protocols offer versatile toolboxes for molecular architects to frame chemistry and materials, nanoscience, and molecular nanotechnology as well as molecular manufactures.
\end{abstract}

\section{Introduction}

Multicomponent organic semiconductors (MOSs) are very important for the functional organic devices [1]. Until now, most of the typical electronic device functionality and performance optimization strongly depend on the synergic interactions among the contradictive components such as electron/hole, $\mathrm{p} / \mathrm{n}$, donor/acceptor and host/guest $[2,3]$. To ingeniously arrange the opposite elements in the device space is a challenge that scientists face in organic electronics. Intramolecular contradiction-uniform systems via molecular engineering that have obvious advantages over physical contradictive systems have been explored such as p-n copolymerization $[4,5]$, bipolar light emitters and molecular heterojunction. The intrinsic merits originated from the molecular features such as efficient energy-transfer process. MOS fully has an advantage over semiconductor blending systems with the drawback of phase separation. Recently, three-component red-green-blue (RGB) polymers show promising single-molecular white light-emitting materials [6-8]. The trend in organic semiconductors is to integrate various different functional moieties into single nanomolecules via covalent molecular engineering process. It is an emergent task to achieve stable and high-performance single-layer devices with MOSs equivalent to those in a multilayer device, although some issues are unresolved, such as unfoldable functionalities. For example, the unified p$\mathrm{n}$ systems are still lagging behind the bulk heterojunction blending systems for polymer solar cells $[9,10]$.

The initial issues are that there are limited flexible methods to integrate various functional moieties into a robust system of MOSs with the suitable positions as well as controllable distance. Framework chemistry and materials offer the methodology to MOSs by means of state-of-the-art 
models with several merits such as rigid shape persistence, cubic backbones, and mesh superstructures. However, the most reported metal-organic frameworks (MOFs) [11] and covalent organic frameworks (COFs) $[12,13]$ do not exhibit any solubility that severely hinders the entry to organic semiconductors. Soluble metal-organic polyhedron (MOPs) [14$16]$ and covalent organic polyhedron (COPs) $[17,18]$ do not easily access. In this background, it is necessary for molecular architects to create the designable organic intramolecular multicomponent systems that are suitable for the MOSs via a feature of facile, concise, green and sustainable syntheses.

Previously, we set up a $\mathrm{BF}_{3} \cdot \mathrm{Et}_{2} \mathrm{O}$-mediated FriedelCrafts reaction of tertiary alcohols [19-21], an atom-economic and classical $\mathrm{C}-\mathrm{H}$ bond functionalization to synthesize a series of complex diarylfluorenes (CDAFs) [22]. Subsequently, this protocol has modified stacked polymer semiconductors for nonvolatile memory devices [23] and light-emitting devices $[24,25]$. Hyperbranched conjugationinterrupted polymers have been made by means of FriedelCrafts polymerization [26, 27]. More recently, morphologydirected molecular designs have been demonstrated using diarylfluorene-modified fullerenes for bulk heterojunction solar cells by our group [28]. Series of works from XIE-HUANG group demonstrate that this approach is effective for function-directed semiconducting materials in organic electronics. However, scientists have never started to explore fluorenol approach and Friedel-Crafts protocols as versatile toolbox toward structure-directed framework, porous, mesh nanomaterials in the realm of nanoscience, and molecular nanotechnology. To this end, we demonstrate the flexible fluorenol approach as an organic nanochemistry method for soluble covalent organic nanoframeworks (CONs). Diarylfluorene-based BPyFBFFA that is easily accessed from Friedel-Craft reaction has complex nanomolecular architecture with a nonplanar geometric shape of three-legged chair (Figure 3). The BPyFBFFA contains multicomponent blue emitting pyrene chromophores, terfluorene and hole-transporting triphenylamine (TPA), which exhibit a stable amorphous blue emitter with a low ionization potential of $5.32 \mathrm{eV}$.

\section{Results and Discussion}

We firstly carried out retrosynthesis analysis of BPyFBFFA as modeling MOSs that has an open framework (Scheme 1). So far, there are two typical divergent and convergent routes for dendrimers, multiarmed or starburst oligomers, and nanosized architectures. For this asymmetry BPyFBFFA, siteselective reaction that is a challenge in organic synthesis would be the prerequirement if the individual divergent route I or convergent route II is workable. To handle the thorny issue, we adopted a hybrid approach of divergent and convergent route to the target molecule, BPyFBFFA, as shown in Scheme 1. We found that $\mathrm{BF}_{3} \cdot \mathrm{OEt}_{2}$ catalyzed electrophilic substitution reactions of 9-arylfluorenol with thiophene, TPA, and their derivatives in nearly quantitative yields that encouraged us exploring the complex BPyFBFFA via the Friedel-Crafts protocol.
BPyFBFFA was synthesized by the divergent and convergent mixture routes that are outlined in Scheme 1. First, we take three times of iterative Friedel-Crafts reactions to BPyFBFFA. In details, BPyFBFFA can be obtained by the Friedel-Crafts reactions of BPyPFBA with blue lightemitting tertiary alcohol (TFOH) at the yield of $70 \%$. The key intermediate of BPyPFBA has been synthesized by the Suzuki cross-coupling reaction of compound 2 with 1pyrenylboronic acid. Friedel-Crafts reactions of PyFA with bromo-substituted fluorene tertiary alcohol enable to synthesize compound 2. Similar processes of Friedel-Crafts reactions and Suzuki coupling reactions have been repeated to give the key intermediate, PyFA. The target BPyFBFFA can be accessed by the simplified two times of iterative FriedelCrafts reactions that undergo the key intermediate of compound 3. The above effective route suggested that $\mathrm{BF}_{3} \cdot \mathrm{OEt}_{2}-$ mediated Friedel-Crafts reaction, combining with the Suzuki reaction, is an efficient method to prepare different twocomponent or three-component complicated electroluminescent nanomolecules. The BPyFBFFA and the key intermediates have good solubility in common organic solvents such as dichloromethane, chloroform and THF that have been characterized by ${ }^{1} \mathrm{H}$ NMR, ${ }^{13} \mathrm{C}$ NMR and matrix-assisted laser desorption/ionization time-of-flight mass spectrometer (MALDI-tof-MS). The target compound has been unambiguously confirmed by the MALDI-tof-MS that exhibits a single peak with molecular weight of 2142.5 (Figure 1), well matched with the calculated molecular weight of $2143 \mathrm{Da}$.

The physical data that includes thermal, electrochemical and optical properties of these organic nanomolecules are collected in Table 1 . The thermal properties of the nanomolecules were evaluated by thermogravimetric analyses (TGA) and differential scan calorimetry (DSC) (See Supplementry Material available online at http://dx.doi.org/ $10.1155 / 2013 / 368202)$. It is found that the decomposition temperatures $\left(T_{d}\right)$ (5\% weight loss) of nanomolecules are above $400^{\circ} \mathrm{C}$. From DSC curves, two intermediates exhibited the glass transition in the second heating cycle with the $T_{g}$ of $147^{\circ} \mathrm{C}$ for PyFA, $218^{\circ} \mathrm{C}$ for BPyFA and $130^{\circ} \mathrm{C}$ for BPyFBFFA. No crystallization exotherm and melting endotherm were observed. As expected, incorporation of diarylfluorenes is beneficial to raising morphological stability. CV measurement was employed by us to investigate the oxidation and reduction behavior of organic nanomolecular frameworks, in order to estimate their HOMO and LUMO energy levels. The reduction and oxidation behaviors of the nanomolecular PyFA, BPyFA and BPyFBFFA were investigated by cyclic voltammetry $(\mathrm{CV})$ in anhydrous dichloromethane. BPyFBFFA has a bandgap of about $2.73 \mathrm{eV}$ that is probably because pyrene causes the reduction of potential with LUMO of $\sim-2.63 \mathrm{eV}$.

Figure 2 depicts the absorption and photoluminescence spectra of the compounds PyFA, BPyFA and BPyFBFFA in THF. The absorption and photoluminescence maxima of PyFA and BPyFA were very similar (Table 1). The peak at $\sim 350 \mathrm{~nm}$ and $\sim 298 \mathrm{~nm}$ in the absorption spectra of PyFA and BPyFA is ascribed to the most prominent $\pi-\pi^{*}$ vibration of chromophore pyrene and triphenylamine according to 


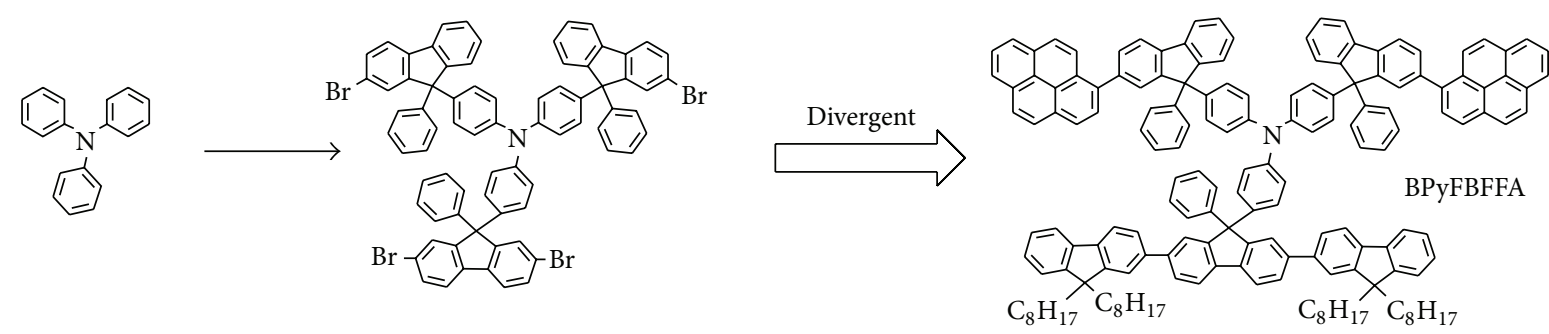

(a)

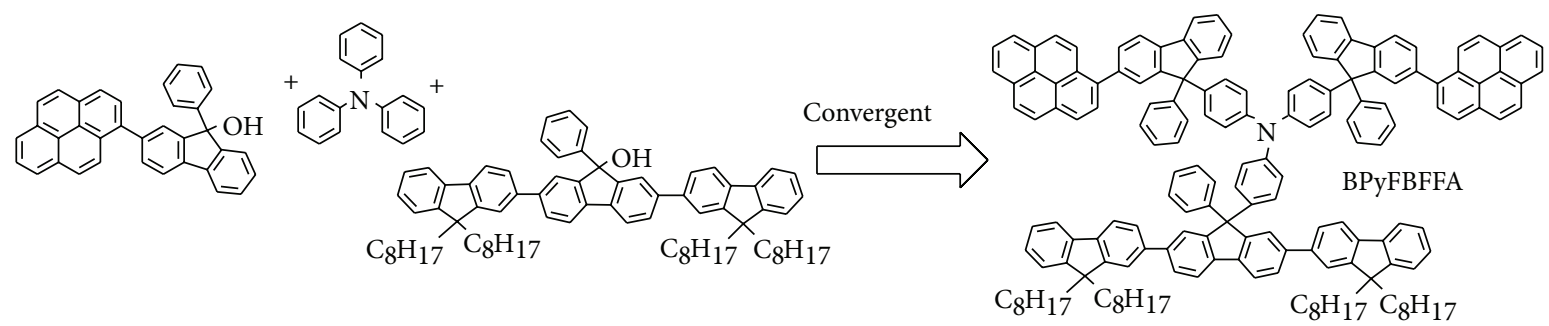

(b)

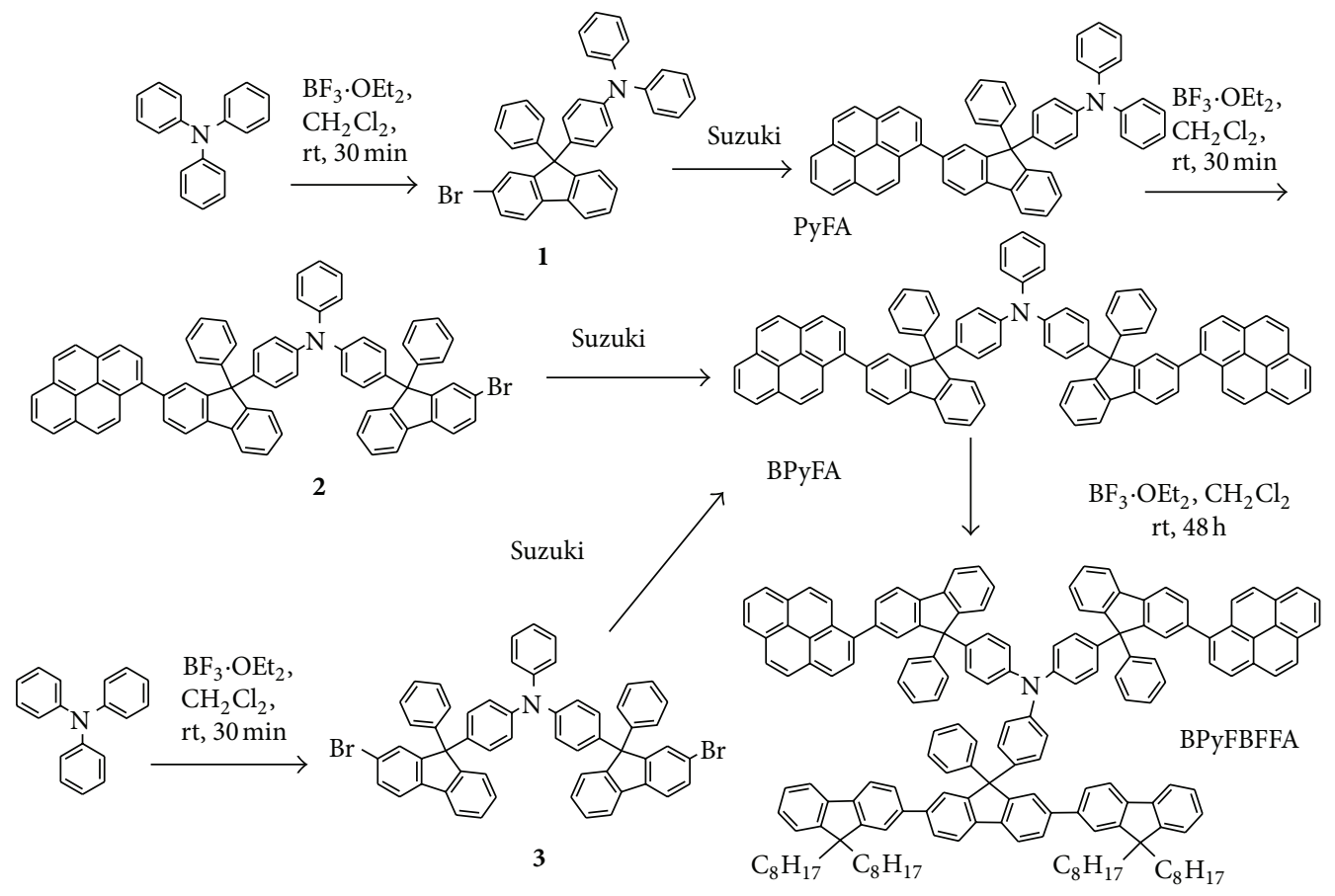

(c)

SCHEME 1: Retrosynthesis analysis of BPyFBFFA: (a) divergent synthetic route, (b) convergent synthetic route, (c) mixture route to BPyFBFFA.

our prevrious observations [22], respectively. Therefore, compared with PyFA, BPyFA with double substitution of pyrene moieties exhibited the relatively increasing intensity of peak at $350 \mathrm{~nm}$. The PL maxima of PyFA and BPyFA in film were obviously red shifted (c.a. $50 \mathrm{~nm}$ ), relative to those in solution presumably because of the improved excimer emission that resulted from strongly $\pi$-stacking between pyrene planes. The absorption and PL maxima of BPyFBFFA in solution are about $350 \mathrm{~nm}$ and $422 \mathrm{~nm}$, respectively. The photoluminescence maxima of BPyFBFFA in solid state thin films were slightly red shifted relative to those in solution presumably because of different dielectric constants in microenvironment. The difference between the precursors and the target BPyFBFFA without excimers suggests the introduction of terfluorene backbone is favorable for the three-dimensional framework to overcome the intermolecular interactions by the increased distance among chromophores.

\section{Conclusions}

In summary, we proposed shape-persistent covalent organic frameworks, polyhedra, nanomolecular architectures as 
TABle 1: Physical data of PyFA, BPyFA and BPyFBFFA.

\begin{tabular}{lcccccccc}
\hline Compound & $\lambda_{\max }{ }^{\mathrm{a}}(\mathrm{nm} / \mathrm{abs})$ & $\lambda_{\max }{ }^{\mathrm{a}}(\mathrm{nm} / \mathrm{PL})$ & $\lambda_{\max }{ }^{\mathrm{b}}(\mathrm{nm} / \mathrm{PL})$ & $T_{d}\left({ }^{\circ} \mathrm{C}\right)^{\mathrm{c}}$ & $T_{g}\left({ }^{\circ} \mathrm{C}\right)^{\mathrm{d}}$ & $(\mathrm{HOMO} / \mathrm{eV})^{\mathrm{e}}$ & $(\mathrm{LUMO} / \mathrm{eV})^{\mathrm{e}}$ & $\mathrm{Band}$ gap \\
\hline PyFA & 298,350 & 405 & 454 & 430 & 147 & -5.29 & -2.51 \\
BPyFA & 298,350 & 421 & 468 & 519 & 218 & -5.36 & -2.63 \\
BPyFBFFA & 349 & 401,422 & 433 & 402 & 130 & -5.32 & 2.78 \\
\hline
\end{tabular}

${ }^{\mathrm{a}}$ Measured in $\mathrm{CHCl}_{3}$ solution; ${ }^{\mathrm{b}}$ film; ${ }^{\mathrm{c}}$ obtained from TGA measurements, $T_{d}$ : decomposition temperature, the temperature was recorded corresponding to a $5 \%$ weight loss; ${ }^{\mathrm{d}}$ obtained from DSC measurements, $T_{g}$ : glass transition temperature. ${ }^{\mathrm{e}} \mathrm{HOMO} / \mathrm{LUMO}=-\left(E_{\text {onset }}-0.05 \mathrm{~V}\right)-4.8 \mathrm{eV}$, where the value $0.05 \mathrm{~V}$ is for FOC versus $\mathrm{Ag} / \mathrm{Ag}^{+}$.

Data: lhxie-2-0003.B2 25 Aug 2006 16:07 Cal: 060313-ZHENG 13 Mar 2006 10:11

Kratos PC Axima CFRplus V2.4.0: mode reflectron, power: 123, P.ext. @ 2142 (bin 113)

$22 \mathrm{mV}[$ sum $=893 \mathrm{mV}]$ profiles $1-41$ unsmoothed-baseline 80

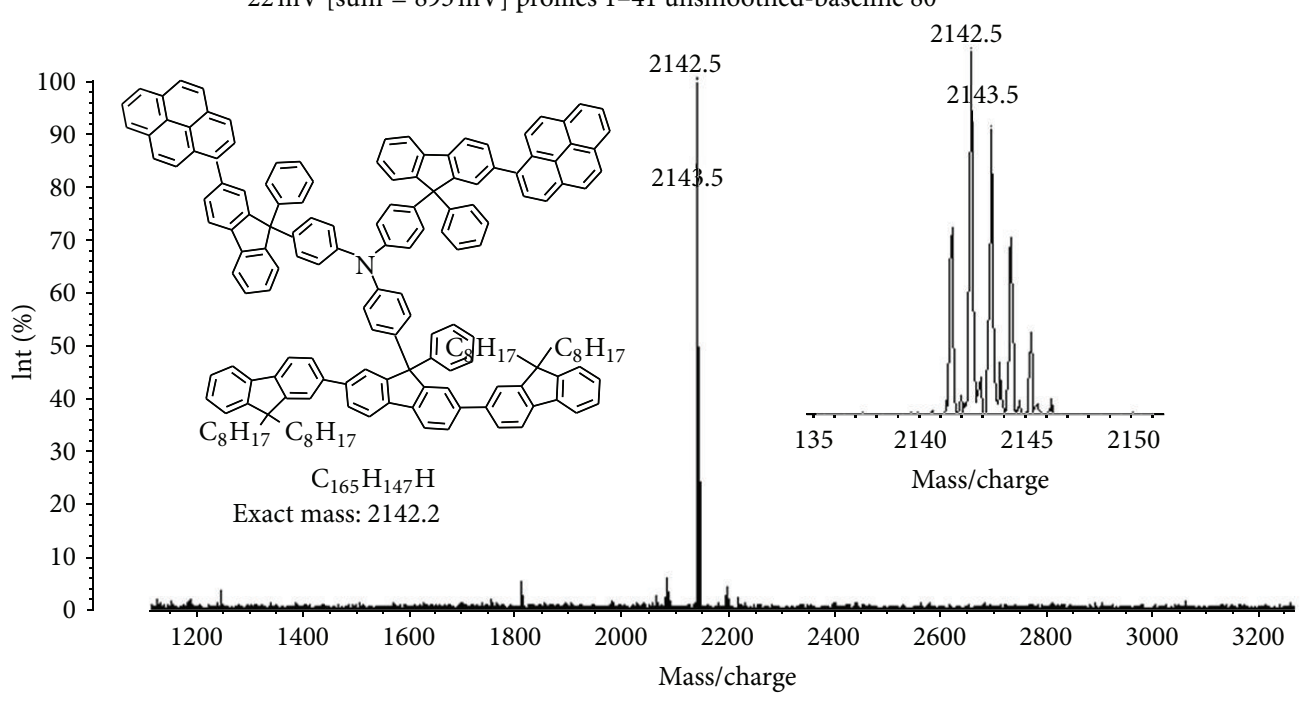

Figure 1: MALDI-tof-MS spectrum of BPyFBFFA.

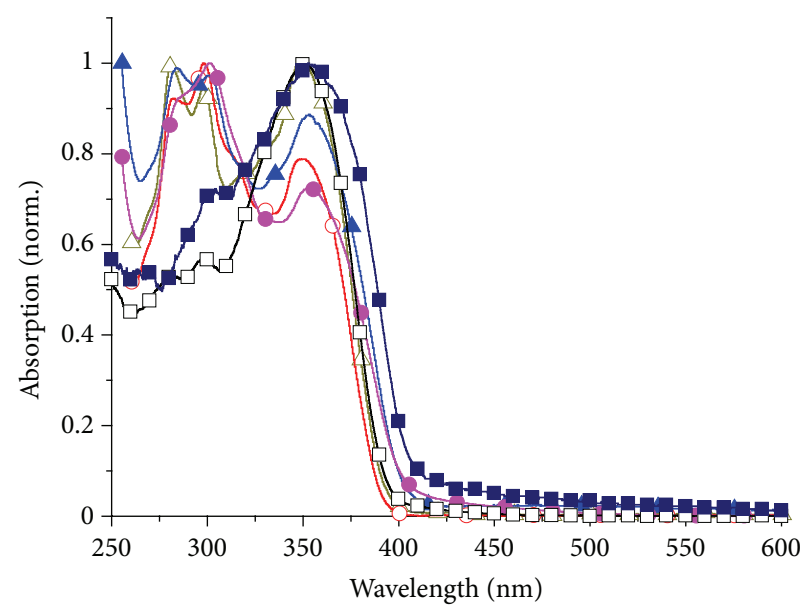

UV

$\multimap-$ PyFA solution

$\neg-$ BPyFA solution

$\rightarrow$ BPyFBFFA solution

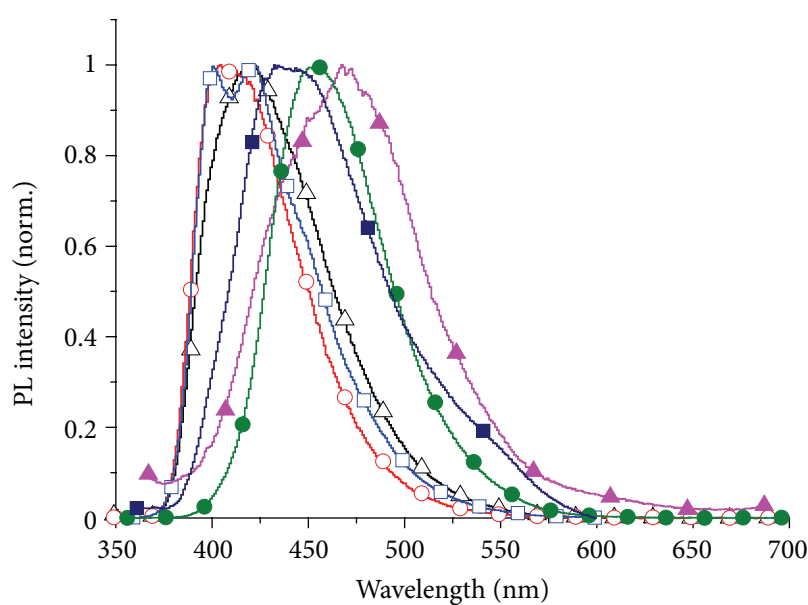

PL

$$
\begin{array}{ll}
-\sim \text { PyFA solution } & \rightarrow \text { PyFA film } \\
-\triangle \text { BPyFA solution } & \rightarrow \text { BPyFA film } \\
-\square \text { BPyFBFFA solution } & \rightarrow-\text { BPyFBFFA film }
\end{array}
$$

(b)

FIgure 2: The UV and PL spectra of PyFA, BPyFA and BPyFBFFA. 


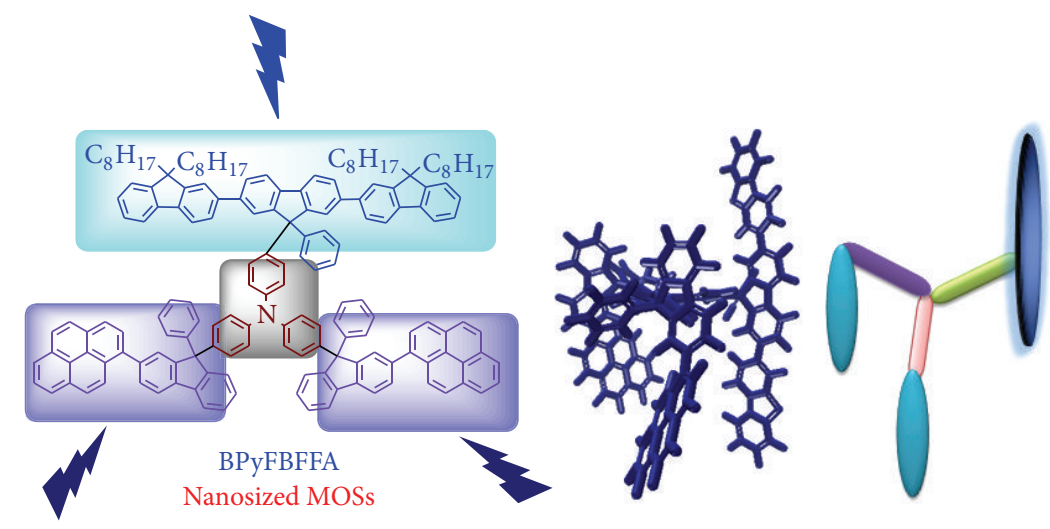

FIGURE 3: The molecular structure of BPyFBFFA, optimized molecular configurations of BPyFBFFA without alkyl substitution, and its cartoon geometric shape that resembles chair.

alternative next-generation organic semiconductors and advanced organic nanomaterials. Fluorenol approaches are one effective and atom-economic bottom-up synthesis to open nanomolecular covalent organic frameworks as organic nanosystems that have been made by retrosynthetic analysis of methodologies. Based on this strategy, BPyFBFFA has been fabricated by iterative Friedel-Crafts reaction combined with Suzuki coupling reactions. BPyFBFFA that contains the oligofluorene tethered with a core of hole-transporting triphenylamine exhibited stable amorphous blue emitting behaviors which is potential multicomponent electroluminescent material. Complex diarylfluorenes (CDAFs) will be potential candidate for organic/polymer porous materials and organic nanomaterials. Fluorenol approaches would offer a versatile platform to organic framework semiconductors for plastic optoelectronics and organic mechatronics.

\section{Experimental Section}

4.1. Chemicals. All the solvents and reagents were purchased from commercial suppliers and were used without further purification, unless noted otherwise. All products were purchased by flash column chromatography which was carried out with Kanto Silica Gel 60N (40-63 $\mu \mathrm{m})$. Spectrochemical-grade solvents were used for optical measurements. Tetra(triphenylphosphine) palladium(II), 1-pyrenylboronic acid, pyrene, 2-bromo-9-fluorenone, bromobenzene and TPA were obtained from Aldrich Chemical Co. Boron trifluoride etherate, potassium carbon-ate, magnesium sulphate, chloroform, and toluene were purchased from Sinopharm Chemical Reagent Co., Ltd. Dichloromethane as dried by anhydrous sodium under room temperature. THF and toluene were dried over sodium benzophenone ketyl anion radical and distilled under a dry nitrogen atmosphere immediately prior to use. 2-bromo-9-phenylfluoren-9-ol and 2,7-dibromo-9-phenylfluorene-9-ol, 4-(2-bromo-9phenyl-fluoren)-N-phenyl-N-(4-(9-phenyl-2-(pyren-1-yl)fluoren) phenyl)aniline, and 9,9,9", $9^{\prime \prime}$-tetraoctyl- $9^{\prime}$-phenyl$\left[2,2^{\prime}: 7^{\prime}, 2^{\prime \prime}\right.$-terfluoren $]-9^{\prime}$-ol were obtained according to our previous literatures $[22,24,25]$.
4.2. Characterization. ${ }^{1} \mathrm{H}-\mathrm{NMR}$ and ${ }^{13} \mathrm{C}-\mathrm{NMR}$ were recorded on a Bruker $400 \mathrm{MHz}$ spectrometer in $\mathrm{d}-\mathrm{CDCl}_{3}$ with tetramethylsilane (TMS) as the interval standard. Mass spectra were recorded on a Shimadzu GCMS-2010P. For the MALDI-TOF MS spectra, the spectra were recorded in reflective mode, and no substrates were used. Element analyses were carried out on an Elementa Analysensysteme $\mathrm{GmbH}$ vario EL III instrument. Absorption spectra were measured with a Shimadzu UV-3150 spectrometer at $25^{\circ} \mathrm{C}$, and emission spectra were recorded on a Shimadzu RF530XPC luminescence spectrometer upon excitation at the absorption maxima. DSC analyses were performed on a Shimadzu DSC-60A instrument at a heating rate of $10^{\circ} \mathrm{C} / \mathrm{min}$. TGA were conducted on a Shimadzu DTG-60H thermogravimetric analyzer under a heating rate of $10^{\circ} \mathrm{C} / \mathrm{min}$. Cyclic voltammetric (CV) studies were conducted at room temperature on the $\mathrm{CHI} 660 \mathrm{E}$ system in a typical three-electrode cell with a platinum sheet working electrode, a platinum wire counter electrode, and a silver/silver nitrate $\left(\mathrm{Ag} / \mathrm{Ag}^{+}\right)$ reference electrode. All electrochemical experiments were carried out under a nitrogen atmosphere at room temperature in an electrolyte solution of $0.1 \mathrm{M}$ tetrabutylammonium hexafluorophosphate $\left(\mathrm{Bu}_{4} \mathrm{NPF}_{6}\right)$ in $\mathrm{CH}_{2} \mathrm{Cl}_{2}$ expect that polymers were coated on platinum plate electrodes in acetonitrile at a sweeping rate of $0.1 \mathrm{~V} / \mathrm{s}$. According to the redox onset potentials of the $\mathrm{CV}$ measurements, the highest occupied molecular orbital (HOMO)/lowest unoccupied energy levels (LUMO) of the materials are estimated based on the reference energy level of ferrocene ( $4.8 \mathrm{eV}$ below the vacuum): $\mathrm{HOMO} / \mathrm{LUMO}=-\left(E_{\text {onset }}-0.05 \mathrm{~V}\right)-4.8 \mathrm{eV}$, where the value $0.05 \mathrm{~V}$ is for ferrocene versus $\mathrm{Ag} / \mathrm{Ag}^{+}$.

4.3. General Procedure for Friedel-Crafts Reactions. A solution of boron trifluoride etherate $\left(\mathrm{BF}_{3} \cdot \mathrm{Et}_{2} \mathrm{O}\right)$ in appropriate dichloromethane $(20 \mathrm{~mL})$ was added dropwise to a mixture solution of tertiary alcohols and aryl substrates in appropriate dichloromethane $(100 \mathrm{~mL})$. The reaction mixture was stirred at $\mathrm{rt}\left(25^{\circ} \mathrm{C}\right)$ under nitrogen until starting material is no longer detectable by TLC ( 2 hours 2 days). Ethanol $(50 \mathrm{~mL})$ and 
water $(150 \mathrm{~mL})$ were successively added to quench the reaction. And then the phases were separated and the aqueous phase was extracted with dichloromethane. The combined dichloromethane layers were washed and dried $\left(\mathrm{MgSO}_{4}\right)$. After removal of the solvent, the remaining crude product was purified by silicone gel chromatography (petroleum ether-dichloromethane) to yield products.

4.4. Synthesis of 4-(2-Bromo-9-phenyl-fluoren-9-yl)-N,N-diphenylaniline (1). Three compounds were prepared following the general procedures above using 2-bromo-9-phenylfluoren-9-ol (0.34 g, $1 \mathrm{mmol}$, 1 equiv.), TPA (2.44 g, $10 \mathrm{mmol}$, 10 equiv.), and $\mathrm{BF}_{3} \cdot \mathrm{Et}_{2} \mathrm{O}$ complex $(0.12 \mathrm{~mL}, 1 \mathrm{mmol})$. The reaction mixture was stirred under nitrogen at room temperature $\left(25^{\circ} \mathrm{C}\right)$ for $30 \mathrm{~min}$. The yield of 4-(2-bromo-9phenyl-fluoren-9-yl)-N,N-diphenylaniline (1) is $90 \%$. The yield of byproduct is $9 \%$. GC-MS (m/z): $565\left[\mathrm{M}^{+}\right]^{1} \mathrm{H}$ NMR (400 MHz, $\left.\mathrm{CDCl}_{3}, \mathrm{ppm}\right): \delta 7.73-7.71(\mathrm{~d}, \mathrm{~J}=7.6 \mathrm{~Hz}, 1 \mathrm{H}), 7.62-$ $7.60(\mathrm{td}, \mathrm{J}=8.0 \mathrm{~Hz}, 1 \mathrm{H}), 7.53-7.53(\mathrm{~s}, 1 \mathrm{H}), 7.48-7.46(\mathrm{dd}, \mathrm{J}=$ $8.0 \mathrm{~Hz}, \mathrm{~J}=2.0 \mathrm{~Hz}, 2 \mathrm{H}), 7.42-7.38(\mathrm{~d}, \mathrm{~J}=7.6 \mathrm{~Hz}, 1 \mathrm{H}), 7.37-7.34$ $(\mathrm{t}, \mathrm{J}=7.2 \mathrm{~Hz}, 1 \mathrm{H}), 7.32-7.25(\mathrm{~d}, \mathrm{~J}=7.6 \mathrm{~Hz}, 1 \mathrm{H}), 7.25-7.19(\mathrm{~m}$, $9 \mathrm{H}), 7.18-7.08$ (d, J = 8.0 Hz, 4H), 7.08-6.97 (m, 4H), 6.916.89 (d, J = 8.4 Hz, 2H). 13C NMR (100 MHz, $\left.\mathrm{CDCl}_{3}, \mathrm{ppm}\right)$ : $\delta 153.63,151.42,147.79,146.70,145.49,139.37,139.17,138.74$, $130.87,129.60,129.43,129.01,128.57,128.32,128.23,127.82$, $127.06,126.45,124.71,123.16,123.12,121.72,121.53,120.42,65.31$.

4.5. Synthesis of $N$-(4-(2-Bromo-9-phenyl-fluoren-9-yl)phe$n y l)-N-(4-(9-p h e n y l-2-($ pyren-2-yl)-fluoren-9-yl)phenyl)aniline (2). The compound was prepared following the general procedures above using 2-bromo-9-phenyl-fluoren-9-ol (0.336 g, $1 \mathrm{mmol}, 1$ equiv.), PyFA ( $0.685 \mathrm{~g}, 1 \mathrm{mmol}, 1$ equiv.), and $\mathrm{BF}_{3} \cdot \mathrm{Et}_{2} \mathrm{O}$ complex $(0.124 \mathrm{~mL}, 1 \mathrm{mmol})$. The yield of target product (2) is $89 \%$. MALDI-TOF-MS (m/z): 1003.5 $\left[\mathrm{M}^{+}\right]$calcd. Found: $1005 .{ }^{1} \mathrm{H} \mathrm{NMR}\left(400 \mathrm{MHz}, \mathrm{CDCl}_{3}, \mathrm{ppm}\right)$ : $\delta$ 8.21-8.17 (m, 2H), 8.12-8.08 (m, 4H), 8.01-7.98 (m, 2H), $7.95-7.89(\mathrm{~m}, 2 \mathrm{H}), 7.86-7.85(\mathrm{~d}, \mathrm{~J}=7.6 \mathrm{~Hz}, 2 \mathrm{H}), 7.72-7.64$ $(\mathrm{m}, 3 \mathrm{H}), 7.59-7.57(\mathrm{~d}, \mathrm{~J}=8.0 \mathrm{~Hz}, 1 \mathrm{H}), 7.50-7.39(\mathrm{~m}, 4 \mathrm{H})$, $7.36-7.31(\mathrm{~m}, 5 \mathrm{H}), 7.27-7.13(\mathrm{~m}, 13 \mathrm{H}), 7.08-7.06(\mathrm{~d}, \mathrm{~J}=7.6 \mathrm{~Hz}$, $2 \mathrm{H}), 6.99-6.88(\mathrm{~m}, 7 \mathrm{H})$. 13C NMR (100 MHz, $\left.\mathrm{CDCl}_{3}, \mathrm{ppm}\right)$ : $\delta 153.62,151.86,151.77,151.41,147.62,146.58,146.29,146.13$, $145.47,140.64,140.09,139.45,139.36,139.15,138.81,137.96$, $131.70,131.15,130.85,130.79,130.17,129.58,129.44,129.22$, $128.99,128.87,128.65,128.55,128.48,128.39,128.29,128.22$, $128.02,127.86,127.81,127.79,127.63,127.04,126.88,126.59$, $126.43,126.23,125.46,125.32,125.27,125.13,125.04,124.98$, $124.86,123.80,123.28,123.26,121.67,121.51,120.53,120.38$, $65.40,65.29$.

4.6. Synthesis of N,N-Bis(4-(2-bromo-9-phenyl-fluoren-9-yl) phenyl)aniline (3). The compound was prepared following the general procedures above using 2-bromo-9-phenyl-fluoren-9-ol (3.36 g, $10 \mathrm{mmol}$, 2 equiv.), TPA (1.33 g, $5 \mathrm{mmol}$, 1 equiv.), and $\mathrm{BF}_{3} \cdot \mathrm{Et}_{2} \mathrm{O}$ complex $(0.62 \mathrm{~mL}, 5 \mathrm{mmol})$. The yield of byproduct 4-(2-Bromo-9-phenyl-fluoren-9-yl)- N,Ndiphenylaniline (1) is lower than $5 \%$. The yield of $N, N-$ bis(4-(2-bromo-9-phenyl-fluoren-9-yl)phenyl)aniline (3) is 83\%. MALDI-TOF-MS (m/z): $883\left[\mathrm{M}^{+}\right] .{ }^{1} \mathrm{H}$ NMR $(400 \mathrm{MHz}$, $\left.\mathrm{CDCl}_{3}, \mathrm{ppm}\right): \delta 7.72-7.70(\mathrm{~d}, \mathrm{~J}=7.6 \mathrm{~Hz}, 2 \mathrm{H}), 7.61-7.55(\mathrm{~d}, \mathrm{~J}=$
$7.6 \mathrm{~Hz}, 2 \mathrm{H}), 7.51$ (s, 2H), 7.47-7.45 (d, J = 7.6 Hz, 2H), 7.38$7.33(\mathrm{~m}, 4 \mathrm{H}), 7.29-7.27(\mathrm{~d}, \mathrm{~J}=7.6 \mathrm{~Hz}, 2 \mathrm{H}), 7.24-7.16(\mathrm{~m}, 12 \mathrm{H})$, $7.08-7.06(\mathrm{~d}, \mathrm{~J}=7.6 \mathrm{~Hz}, 2 \mathrm{H}), 7.01-6.98(\mathrm{~d}, \mathrm{~J}=7.6 \mathrm{~Hz}, 5 \mathrm{H}), 6.90-$ $6.88(\mathrm{~d}, \mathrm{~J}=7.6 \mathrm{~Hz}, 4 \mathrm{H}) .{ }^{13} \mathrm{C} \mathrm{NMR}\left(100 \mathrm{MHz}, \mathrm{CDCl}_{3}, \mathrm{ppm}\right)$ : $\delta$ 153.59, 151.38, 147.49, 146.47, 145.45, 139.37, 139.16, 139.01, $130.87,129.54,129.46,129.02,128.57,128.32,128.22,127.82$, $127.06,126.44,125.16,123.49,123.43,121.71,121.52,120.41$, 65.31 .

4.7. Synthesis of $\mathrm{N}, \mathrm{N}$-Bis(4-(2-bromo-9-phenyl-fluoren-9-yl) phenyl)-4-(9-phenyl-2-(pyren-1-yl)-fluoren-9-yl)aniline. The compound was prepared following the general procedures above using 2-bromo-9-phenyl-fluoren-9-ol (0.672 g, $2 \mathrm{mmol}$, 2 equiv.), PyFA ( $0.685 \mathrm{~g}, 1 \mathrm{mmol}, 1$ equiv.), and $\mathrm{BF}_{3} \cdot \mathrm{OEt}_{2}$ complex $(0.124 \mathrm{~mL}, 1 \mathrm{mmol})$. The yield of target product is $75 \%$. MALDI-TOF-MS $(\mathrm{m} / \mathrm{z}): 1321.2\left[\mathrm{M}^{+}\right]$calcd. Found: $1323 .{ }^{1} \mathrm{H}$ NMR $\left(400 \mathrm{MHz}, \mathrm{CDCl}_{3}, \mathrm{ppm}\right): \delta 8.19-8.17$ $(\mathrm{d}, \mathrm{J}=8.0 \mathrm{~Hz}, 2 \mathrm{H}), 8.11-8.04(\mathrm{~m}, 4 \mathrm{H}), 8.01-7.96(\mathrm{~m}, 2 \mathrm{H})$, $7.94-7.89(\mathrm{~m}, 2 \mathrm{H}), 7.85-7.83(\mathrm{~d}, \mathrm{~J}=7.2 \mathrm{~Hz}, 2 \mathrm{H}), 7.71-7.63(\mathrm{~m}$, $4 \mathrm{H}), 7.58-7.56(\mathrm{~d}, \mathrm{~J}=8.0 \mathrm{~Hz}, 2 \mathrm{H}), 7.49-7.39(\mathrm{~m}, 6 \mathrm{H}), 7.34-$ $7.29(\mathrm{~m}, 7 \mathrm{H}), 7.24-7.12(\mathrm{~m}, 17 \mathrm{H}), 6.98-6.96(\mathrm{~d}, \mathrm{~J}=8.8 \mathrm{~Hz}$, $4 \mathrm{H}), 6.93-6.87(\mathrm{~m}, 6 \mathrm{H}) .{ }^{13} \mathrm{C} \mathrm{NMR}\left(100 \mathrm{MHz}, \mathrm{CDCl}_{3}, \mathrm{ppm}\right)$ : $\delta 153.56,151.83,151.76,151.36,146.29,146.09,145.99,145.42$, $140.64,140.36,140.07,139.44,139.34,139.16,137.95,128.92$, $129.12,131.69,131.13,130.85,130.78,130.19,129.56,129.22$, $129.01,128.84,128.64,128.5,128.47,128.38,128.31,128.25$, $128.03,127.87,127.79,127.61,127.03,126.87,126.59,126.42$, $126.24,125.46,125.31,125.26,125.12,125.01,124.87,124.17$, $123.74,121.66,121.51,120.53,120.36,65.39,65.29$.

4.8. Synthesis of N,N-Bis(4-(2-(pyren-1-yl)- 9-phenylfluoren9-yl)phenyl)-4-(2,7-bis(9,9-dioctylfluoren-2-yl)-9-phenyl-fluoren-9-yl)aniline (BPyFBFFA). The target molecule was prepared following the general procedures above using $9,9,9^{\prime \prime}, 9^{\prime \prime}$-tetraoctyl-9' - phenyl- $\left[2,2^{\prime}: 7^{\prime}, 2^{\prime \prime}\right.$-terfluoren $]-9^{\prime}$-ol $(3.043 \mathrm{~g}, 2.94 \mathrm{mmol})$, BPyFA $(3.307 \mathrm{~g}, 2.94 \mathrm{mmol})$, and $\mathrm{BF}_{3} \cdot \mathrm{Et}_{2} \mathrm{O}$ complex $(439.4 \mu \mathrm{L}, 3.46 \mathrm{mmol})$. The reaction mixture was stirred at $\mathrm{rt}\left(25^{\circ} \mathrm{C}\right)$ under nitrogen for $48 \mathrm{~h}$. The yield of BPyFBFFA is $70 \%$. MALDI-TOF-MS $(\mathrm{m} / \mathrm{z}):\left[\mathrm{M}^{+}\right]$ calcd. For $\mathrm{C}_{165} \mathrm{H}_{147} \mathrm{~N}, 2143$ Found: 2142 .

4.9. General Procedure for Suzuki Reactions, Taking N-phenyl-N-(4-(2-(pyren-1-yl)-9-phenyl-fluoren-9-yl)phenyl)aniline $(P y F A)$ as an Example. A typical preparation procedure is as follows. In a three-necked schlenk flask $(150 \mathrm{~mL})$, 4-(2-bromo-9-phenyl-fluoren-9-yl)-N,N-diphenylaniline (1) (565 mg, $1 \mathrm{mmol}$ ), 1-pyrenylboronic acid (322 mg, $1.3 \mathrm{mmol}$, $1.3 \mathrm{eq}$ ), and tetra(triphenylphosphine) palladium (0) (80 mg) were added. The flask was evacuated and back filled with nitrogen atmosphere over three times, after which degassed toluene $(30 \mathrm{~mL})$ and $\mathrm{K}_{2} \mathrm{CO}_{3}$ aqueous solution $(2 \mathrm{M}, 5 \mathrm{~mL}$, $10 \mathrm{e}$ equiv.) were injected into the flask through syringe. The mixture was heated up to $90^{\circ} \mathrm{C}$ and stirred for 2 days. The solvent was removed under vacuum. The mixture was purified by silica gel chromatography (petroleum ether) to afford pale yellow powder (548 mg, 80\%). MALDI-TOF-MS $(\mathrm{m} / \mathrm{z}):\left[\mathrm{M}^{+}\right]$calcd. For $\mathrm{C}_{53} \mathrm{H}_{35} \mathrm{~N}, 685.3$; Found: 685.5. ${ }^{1} \mathrm{H}$ NMR (400 MHz, $\left.\mathrm{CDCl}_{3}, \mathrm{ppm}\right): \delta 8.22-8.18(\mathrm{t}, \mathrm{J}=7.6 \mathrm{~Hz}$, 
$2 \mathrm{H}), 8.16-8.18(\mathrm{~d}, \mathrm{~J}=8.8 \mathrm{~Hz}, 2 \mathrm{H}), 8.09$ (s, 2H), 8.03-8.01 $(\mathrm{t}, 2 \mathrm{H}), 7.97-7.93(\mathrm{t}, \mathrm{J}=7.6 \mathrm{~Hz}, 2 \mathrm{H}), 7.89-7.87(\mathrm{~d}, \mathrm{~J}=7.6 \mathrm{~Hz}$, $1 \mathrm{H}), 7.77$ (s, 1H), 7.69-7.67 (d, J = 7.6 Hz, 1H), 7.52-7.50 (d, J $=7.6 \mathrm{~Hz}, 1 \mathrm{H}), 7.46-7.42(\mathrm{t}, \mathrm{J}=7.6 \mathrm{~Hz}, 1 \mathrm{H}), 7.37-7.34(\mathrm{~m}, 3 \mathrm{H})$, 7.27-7.21 (m, 7H), 7.19-7.17 (d, J = 8.4 Hz, 2H), 7.11-7.09 (d, J = $7.6 \mathrm{~Hz}, 2 \mathrm{H}), 7.02-6.96(\mathrm{~m}, 4 \mathrm{H}) .{ }^{13} \mathrm{C} \mathrm{NMR}\left(100 \mathrm{MHz}, \mathrm{CDCl}_{3}\right.$, ppm): $\delta 151.88,151.77,147.91,146.54,146.21,140.64,140.11$, $139.86,139.46,137.95,131.711,131.15,130.79,130.22,129.45$, $129.23,128.91,128.63,128.53,128.42,128.05,127.91,127.86$, $127.68,126.98,126.64,126.28,125.48,125.37,125.27,125.16$, $125.01,124.92,124.56,123.51,122.99,120.61,120.49,65.41$.

N,N-bis(4-(2-(pyren-1-yl)-9-phenyl-fluoren-9-yl)phenyl)aniline (BPyFA). The target molecule was prepared following the general procedures above. $R_{f}=0.12$ (petroleum ether). MALDI-TOF-MS (m/z): $\left[\mathrm{M}^{+}\right]$calcd. For $\mathrm{C}_{88} \mathrm{H}_{55} \mathrm{~N}$, 1125.4, Found: 1125.6. ${ }^{1} \mathrm{H} \mathrm{NMR}\left(400 \mathrm{MHz}, \mathrm{CDCl}_{3}, \mathrm{ppm}\right)$ : $\delta$ 8.17-8.14 (t, 4H), 8.09-8.04 (m, 8H), 7.96-7.91 (m, 6H), $7.88-7.83(\mathrm{t}, 4 \mathrm{H}), 7.71(\mathrm{~s}, 2 \mathrm{H}), 7.64-7.62(\mathrm{~m}, 2 \mathrm{H}), 7.46-7.44$ $(\mathrm{m}, 2 \mathrm{H}), 7.42-7.38(\mathrm{t}, \mathrm{J}=7.6 \mathrm{~Hz}, 2 \mathrm{H}), 7.31-7.27(\mathrm{~m}, 6 \mathrm{H})$, 7.25-7.15 (m, 8H), 7.14-7.07 (m, 6H), 6.99-6.92 (m, 5H). ${ }^{13} \mathrm{C}$ NMR (100 MHz, $\left.\mathrm{CDCl}_{3}, \mathrm{ppm}\right): \delta 151.82,151.74,147.71,146.36$, $146.158,140.61,140.05,139.87,139.41,137.89,137.81,131.64$, $131.08,130.72,130.17,129.43,129.17,128.85,128.57,128.55$, $128.48,128.37,128.29,128.01,127.84,127.80,127.60,126.88$, $126.57,126.21,125.42,125.23,125.19,125.05,124.97,124.89$, $124.85,123.57,123.15,120.54,120.39,65.37$.

\section{Authors' Contributions}

G.- W. Zhang and L. Wang contributed equally to this work.

\section{Acknowledgments}

This project was supported by the National Key Basic Research Program of China (973) (2009CB930600), National Natural Science Foundation of China (61106058, 51273092, 50428303, 61136003, 21274064, 21144004, 60876010, BZ2010043, 20974046, 20774043, and 51173081), The Program for New Century Excellent Talents in University (NCET-11-0992), Natural Science Foundation of Jiangsu Province, China (SBK201122680, BK2009025, 10KJB510013, BK2011761, BK2008053, and SJ209003). L. H. Xie thanks Jiangsu Overseas Research and Training Program for University Prominent Young and Middle-Aged Teachers and Presidents.

\section{References}

[1] L. H. Xie, C. R. Yin, W. Y. Lai, Q. L. Fan, and W. Huang, "Polyfluorene-based semiconductors combined with various periodic table elements for organic electronics," Progress in Polymer Science, vol. 37, no. 9, pp. 1192-1264, 2012.

[2] L. H. Xie, Y. Z. Chang, J. F. Gu et al., "Design of organic/polymeric $\pi$-semiconductors: the four-element principle," Acta Physico-Chimica Sinica, vol. 26, no. 7, pp. 1784-1794, 2010.

[3] L. H. Xie, W. Huang, and IEEE, "Bandgaps enigeering in lightemitting polymers via from $\mathrm{p}-\mathrm{n}$ diblock compolymerization to inorganic/organic hybridization," in 14th OptoElectronics and Communications Conference (OECC '09), pp. 492-493, July 2009.
[4] J. F. Pan, S. J. Chua, and W. Huang, "Tuning redox behavior and emissive wavelength of conjugated polymers by $\mathrm{p}-\mathrm{n}$ diblock structures-a theoretical investigation," Synthetic Metals, vol. 110 , no. 1, pp. 85-89, 2000.

[5] W. Huang, H. Meng, W. L. Yu, J. Pei, Z. K. Chen, and Y. H. Lai, "A novel series of $\mathrm{p}-\mathrm{n}$ diblock light-emitting copolymers based on oligothiophenes and 1,4-Bis(oxadiazolyl)-2,5-dialkyloxybenzene," Macromolecules, vol. 32, no. 1, pp. 118-126, 1999.

[6] J. Liu, Q. G. Zhou, Y. X. Cheng et al., “The first single polymer with simultaneous blue, green, and red emission for white electroluminescence," Advanced Materials, vol. 17, no. 24, pp. 29742978, 2005.

[7] J. Liu, L. Chen, S. Shao et al., "Three-color white electroluminescence from a single polymer system with blue, green and red dopant units as individual emissive species and polyfluorene as individual polymer host," Advanced Materials, vol. 19, no. 23, pp. 4224-4228, 2007.

[8] Z. Zhang, Q. Wang, Y. Dai, Y. Liu, L. Wang, and D. Ma, "High efficiency fluorescent white organic light-emitting diodes with red, green and blue separately monochromatic emission layers," Organic Electronics, vol. 10, no. 3, pp. 491-495, 2009.

[9] D. Venkataraman, S. Yurt, B. H. Venkatraman, and N. Gavvalapalli, "Role of molecular architecture in organic photovoltaic cells," Journal of Physical Chemistry Letters, vol. 1, no. 6, pp. 947958, 2010.

[10] J. Weickert, R. B. Dunbar, H. C. Hesse, W. Wiedemann, and L. Schmidt-Mende, "Nanostructured organic and hybrid solar cells," Advanced Materials, vol. 23, no. 16, pp. 1810-1828, 2011.

[11] M. D. Allendorf, A. Schwartzberg, V. Stavila, and A. A. Talin, "A roadmap to implementing metal-organic frameworks in electronic devices: challenges and critical directions," Chemistry, vol. 17, no. 41, pp. 11372-11388, 2011.

[12] A. P. Côté, A. I. Benin, N. W. Ockwig, M. O’Keeffe, A. J. Matzger, and O. M. Yaghi, "Chemistry: porous, crystalline, covalent organic frameworks," Science, vol. 310, no. 5751, pp. 1166-1170, 2005.

[13] H. M. El-Kaderi, J. R. Hunt, J. L. Mendoza-Cortes et al., "Designed synthesis of 3D covalent organic frameworks," Science, vol. 316, no. 5822, pp. 268-272, 2007.

[14] M. Eddaoudi, J. Kim, J. B. Wachter, H. K. Chae, M. O'Keeffe, and O. M. Yaghi, "Porous metal-organic polyhedra: $25 \AA$ cuboctahedron constructed from $12 \mathrm{Cu}_{2}\left(\mathrm{CO}_{2}\right)_{4}$ paddle-wheel building blocks," Journal of the American Chemical Society, vol. 123, no. 18, pp. 4368-4369, 2001.

[15] J. J. I. V. Perry, J. A. Perman, and M. J. Zaworotko, “Design and synthesis of metal-organic frameworks using metal-organic polyhedra as supermolecular building blocks," Chemical Society Reviews, vol. 38, no. 5, pp. 1400-1417, 2009.

[16] D. J. L. Tranchemontagne, Z. Ni, M. O’Keeffe, and O. M. Yaghi, "Reticular chemistry of metal-organic polyhedra," Angewandte Chemie, vol. 47, no. 28, pp. 5136-5147, 2008.

[17] J. Lohrman, C. Zhang, W. Zhang, and S. Ren, "Semiconducting carbon nanotube and covalent organic polyhedron-C-60 nanohybrids for light harvesting," Chemical Communications, vol. 48, no. 6717, pp. 8377-8379, 2012.

[18] Y. Jin, A. Jin, R. McCaffrey, H. Long, and W. Zhang, "Design strategies for shape-persistent covalent organic polyhedrons (COPs) through imine condensation/metathesis," Journal of Organic Chemistry, vol. 77, no. 17, pp. 7392-7400, 2012. 
[19] L. H. Xie, X. Y. Hou, Y. R. Hua et al., "Facile synthesis of complicated 9, 9-diarylfluorenes based on $\mathrm{BF}_{3} \cdot \mathrm{Et}_{2} \mathrm{O}$-mediated FriedelCrafts reaction," Organic Letters, vol. 8, no. 177, pp. 3701-3704, 2006.

[20] L. H. Xie, X. Y. Hou, C. Tang et al., "Novel H-shaped persistent architecture based on a dispirlo building block system," Organic Letters, vol. 8, no. 7, pp. 1363-1366, 2006.

[21] L. H. Xie, F. Liu, C. Tang et al., "Unexpected one-pot method to synthesize spiro[fluorene-9,9'-xanthene] building blocks for blue-light-emitting materials," Organic Letters, vol. 8, no. 13, pp. 2787-2790, 2006.

[22] L. H. Xie, X. Y. Hou, Y. R. Hua et al., "Facile synthesis of complicated 9,9-diarylfluorenes based on $\mathrm{BF}_{3} \cdot \mathrm{Et}_{2} \mathrm{O}$-mediated FriedelCrafts reaction," Organic Letters, vol. 8, no. 17, pp. 3701-3704, 2006.

[23] L. H. Xie, Q. D. Ling, X. Y. Hou, and W. Huang, "An effective Friedel-Crafts postfunctionalization of poly(N-vinylcarbazole) to tune carrier transportation of supramolecular organic semiconductors based on $\pi$-stacked polymers for nonvolatile flash memory cell," Journal of the American Chemical Society, vol. 130, no. 7, pp. 2120-2121, 2008.

[24] C. R. Yin, S. H. Ye, J. Zhao et al., "Hindrance-functionalized $\pi$-stacked polymer host materials of the Cardo-type carbazolefluorene hybrid for solution-processable blue electrophosphorescent devices," Macromolecules, vol. 44, no. 12, pp. 4589-4595, 2011.

[25] L. H. Xie, X. Y. U. Deng, L. Chen et al., "A $\pi$-stacked and conjugated hybrid based on poly(N-vinylcarbazole) postfunctionalized with terfluorene for stable deep-blue hole-transporting materials," Journal of Polymer Science A, vol. 47, no. 20, pp. 52215229, 2009.

[26] Z. D. Liu, Y. Z. Chang, C. J. Ou et al., " $\mathrm{BF}_{3} \cdot \mathrm{Et}_{2} \mathrm{O}$-mediated Friedel-Crafts $\mathrm{C}-\mathrm{H}$ bond polymerization to synthesize $\pi$-conjugation-interrupted polymer semiconductors," Polymer Chemistry, vol. 2, no. 10, pp. 2179-2182, 2011.

[27] F. Liu, J. Q. Liu, R. R. Liu et al., "Hyperbranched framework of interrupted $\pi$-conjugated polymersend-capped with high carrier-mobility moieties for stable light-emitting materials with low driving voltage," Journal of Polymer Science A, vol. 47, no. 23, pp. 6451-6462, 2009.

[28] B. Y. Ren, C. J. Ou, C. Zhang et al., "Diarylfluorene-modified fulleropyrrolidine acceptors to tune aggregate morphology for solution-processable polymer/fullerene bulk-heterojunction solar cells," Journal of Physical Chemistry C, vol. 116, no. 16, pp. 8881-8887, 2012. 

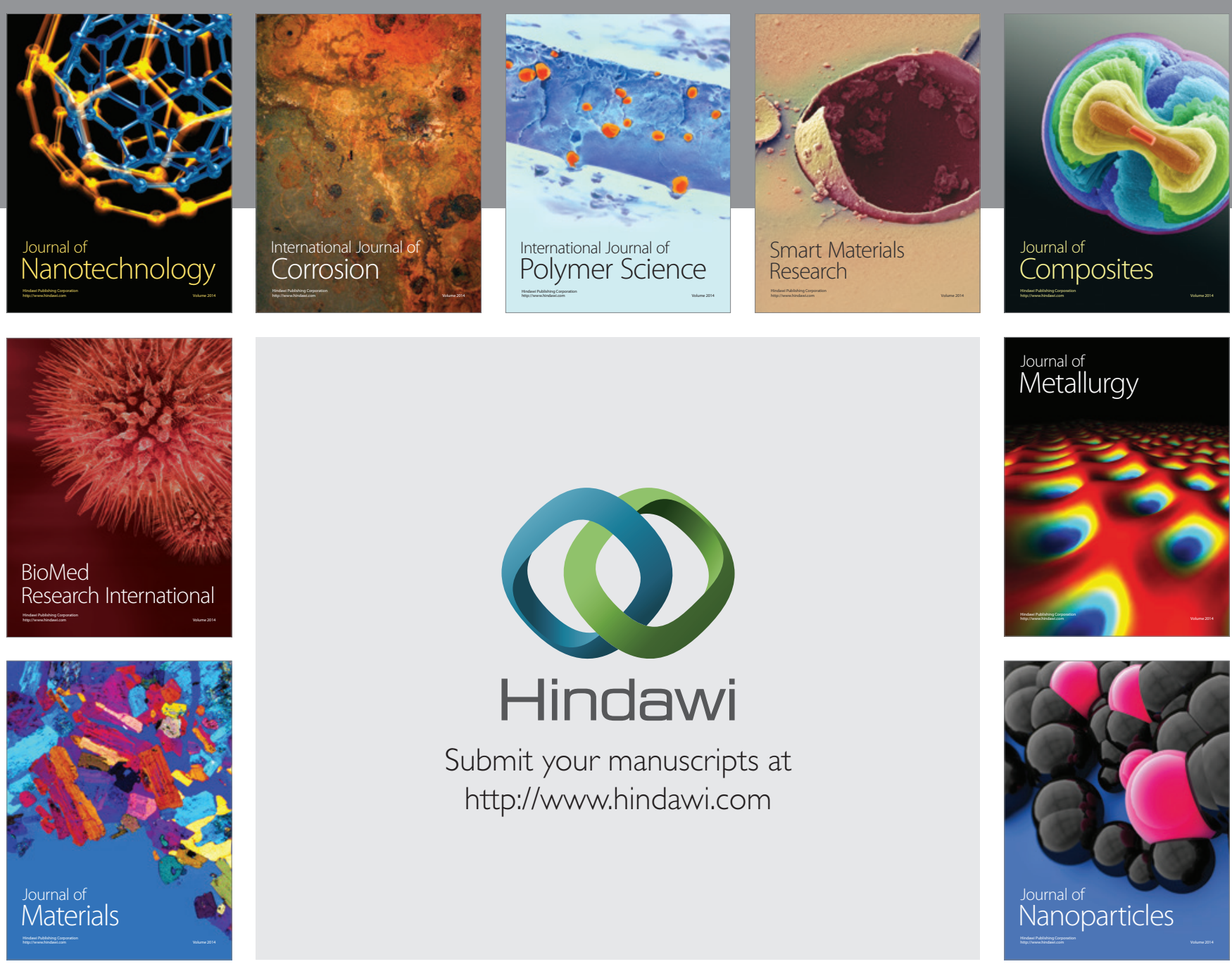

Submit your manuscripts at http://www.hindawi.com
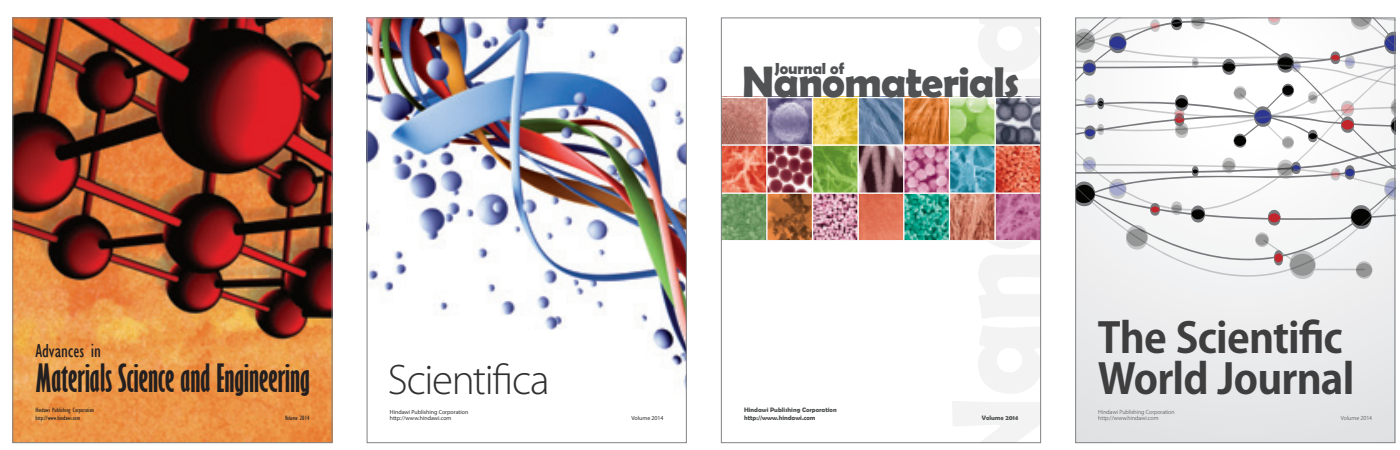

\section{The Scientific World Journal}
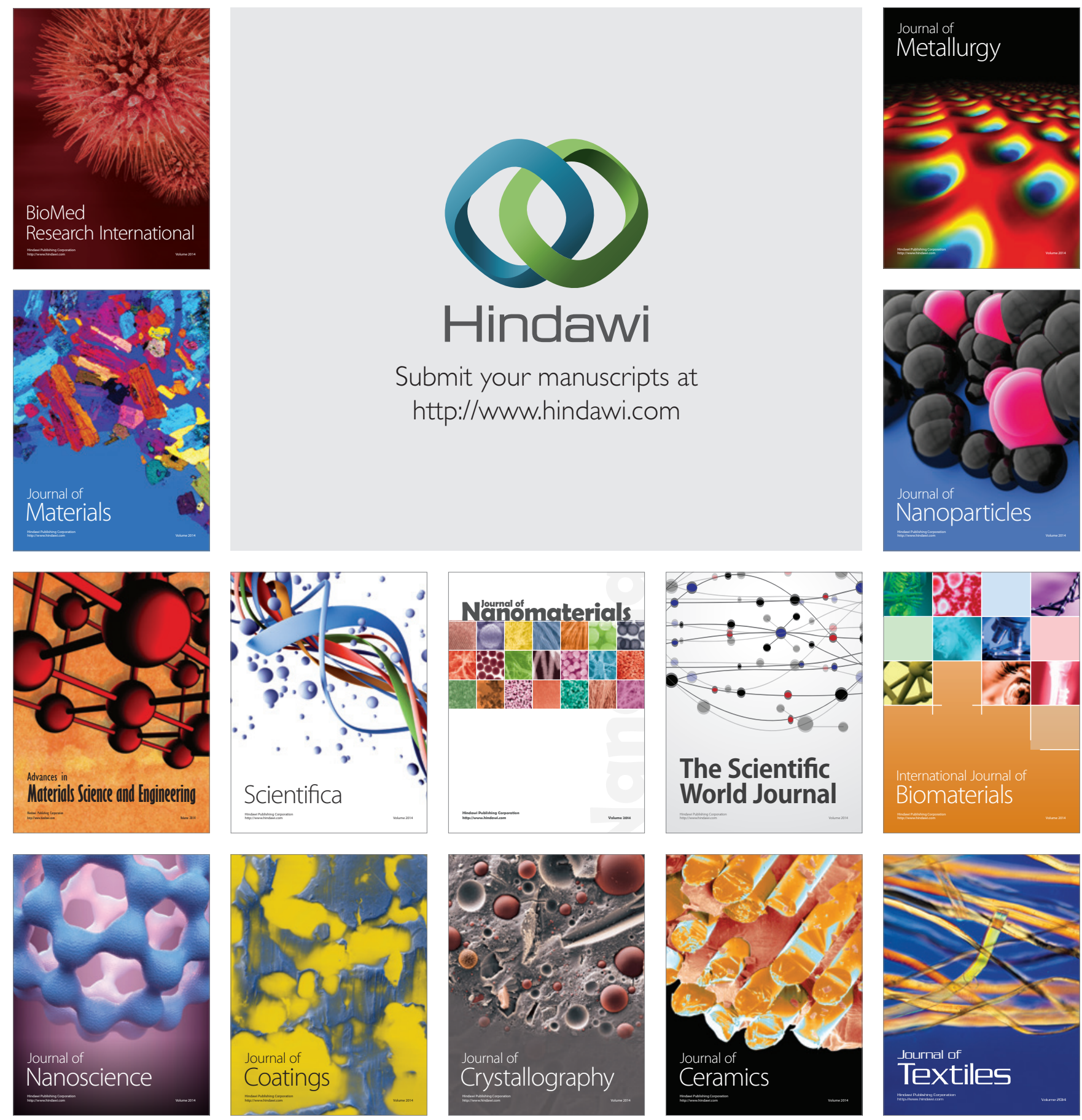